\title{
CHANGES IN THE INTENSITY OF FREE RADICAL LIPID OXIDATION IN PATIENTS WITH BRONCHIAL ASTHMA WITH CONCOMITANT CHRONIC NON-CALCULOUS CHOLECYSTITIS
}

\author{
Tetiana Dudka $^{1}$, Olha Mandryk ${ }^{2}$, Yana Toderika ${ }^{3}$, Ivanna Rachynska ${ }^{4}$, \\ Zakhar Marfiuk ${ }^{5}$
}

\begin{abstract}
:
INTRODUCTION: The incidence rate of chronic non-calculous cholecystitis (CNCC) in the population is 35-38\%, and in elderly patients it reaches to $65-72 \%$. Free radical lipid oxidation (FRLO) plays a significant role in the development and progression of bronchial asthma (BA). The initiators of FRLO excessive activation can be the following: hypoxia, inflammation, immune damage to membranes and the imperfection of the antioxidant defense.

OBJECTIVE: To compare the intensity of FRLO processes in patients with BA and comorbid CNCC, and patients with BA and CNCC each without any comorbidities.

METHODS: The study was performed on 92 patients: 30 patients with BA (group 1), 30 patients with BA and comorbid CNCC (group 2), and 32 patients with CNCC (group 3). The control group consisted of 30 practically healthy persons (PHP). The number of compounds with isolated double bonds (IDB), diene conjugates (DC), ketodienes and conjugated trienes (K/CT), and malonic aldehyde (MA) in erythrocytes and blood plasma were determined.

RESULTS: In groups 1, 2, and 3, the content of IDB was higher in comparison with PHP by 1.4, 1.7, and 1.6 times respectively. In group 1, plasma K/CT was $12.0 \%$ higher, and DC was 1.5 times higher compared to the PHP group. In group 2, DC and K/CT were higher by 1.7 times and by $21.7 \%$ as compared with PHP. In group 1, plasma MA and red blood cell MA were higher by $18.0 \%$ and $29.8 \%$. The highest content of plasma MA and red blood cell MA in group 2 of patients was $69.8 \%$ and $54.3 \%$ respectively. In group 3, plasma MA was $34.7 \%$ higher, and red blood cell MA was $44.4 \%$ higher compared to the normal values.

CONCLUSIONS: Intensification of FRLO processes leads to disruption of microcirculation and metabolic processes in the bronchial epithelium, supports local inflammatory process in the gallbladder and bronchi and promotes inhibition of tissue respiration with increased tissue hypoxia, which, in turn, leads to the progression of broncho-obstruction.
\end{abstract}

UDC Classification: 616.248, DOI: https://doi.org/10.12955/pmp.v1.90

Keywords: Chronic non-calculous cholecystitis, bronchial asthma, free radical lipid oxidation.

\section{Introduction}

Among chronic diseases of the biliary system, chronic non-calculous cholecystitis (CNCC) is most prevalent, with the incidence rate of $35-38 \%$ in the population similar to atherosclerosis and increases to $65-72 \%$ in the elderly patients (Ilyuhina, 2010). CNCC is considered as a physical as well as chemical stage of cholesterol cholelithiasis so timely and adequate preventive therapy can stop the progression of gallstone disease (GD) and its complications (Gorbunov, 2011). More than 2.5 million biliary surgeries are performed annually in the world, and $80 \%$ of cases of cholecystectomy are performed for cholesterol cholelithiasis on patients in the working age group, out of which $12-20 \%$ are accompanied by a complicated course (Conte \& Fraquelli, 2011).

Free radical lipid oxidation (FRLO) plays a significant role in the development and progression of bronchial asthma (BA), which is one of the most important mechanisms for regulating the state of membranes and cells (Goryachkina, 2010). The excessive activation of FRLO can be due to the following initiators: hypoxia (Dozor, 2010), inflammation, infection, immune damage to membranes, the imperfection of the antioxidant defense, and others (Cho \& Moon, 2010). The chronic inflammatory process in the gallbladder plays a special role in this process, especially when it is caused not only by bacterial and fungal allergens, but also by chronic contamination in the biliary tract of protozoa and helminths (Galimova, 2010).

\footnotetext{
${ }^{1}$ Higher State Educational Establishment of Ukraine «Bukovinian State Medical University», Chernivtsi, Ukraine, tetyana.dudka@bsmu.edu.ua

${ }^{2}$ Higher State Educational Establishment of Ukraine «Bukovinian State Medical University», Chernivtsi, Ukraine, mandryk.olha@bsmu.edu.ua

${ }^{3}$ Higher State Educational Establishment of Ukraine «Bukovinian State Medical University», Chernivtsi, Ukraine, ianusca12@gmail.com

${ }^{4}$ Higher State Educational Establishment of Ukraine «Bukovinian State Medical University», Chernivtsi, Ukraine, sasoring56@gmail.com

${ }^{5}$ Higher State Educational Establishment of Ukraine «Bukovinian State Medical University», Chernivtsi, Ukraine,zmarfuk98@gmail.com
} 


\section{Aim}

The objective of the study was to compare the intensity of FRLO processes in patients having bronchial asthma comorbid with CNCC and patients with BA and CNCC without any comorbidity.

\section{Material and Methods of Investigation}

The study was performed on 92 patients: 30 patients with mild to moderate persistent BA (group 1), 30 patients with mild to and moderate persistent BA with comorbid chronic non-calculous cholecystitis in the acute phase (group 2), and 32 patients with CNCC in the acute phase (group 3). The control group consisted of 30 practically healthy persons (PHP) in the corresponding age group.

The content of intermediates was determined in the examined patients for the number of compounds with isolated double bonds (IDB), diene conjugates (DC), ketodienes, conjugated trienes (K/CT), malonic aldehyde (MA) one of the final contents in erythrocytes and blood plasma of FRLO products.

Patients were examined during an exacerbation of the disease; at the beginning and at the end of the treatment. The diagnosis of BA was determined according to the standard criteria, while using the classification of ICD-10 (International classification of diseases, tenth revision, clinical modification (2020)), as well as the order of the Ministry of Health of Ukraine, about approval of Protocols for providing assistance to patients in pulmonary medicine. The CNCC diagnosis and its phases were determined on the basis of clinical symptoms and the results of instrumental studies (ultrasound examination of the gallbladder, cholecystography, multi-stage 6-phase duodenal sounding (DS) with microscopy, microbiological and biochemical examination of the gallbladder portion of bile) are reported as per the order of the Ministry of Health of Ukraine, taking into account the ISD, $10^{\text {th }}$ revision. The type of gallbladder dyskinesia and Oddi sphincter dysfunction were determined based on the data provided by dynamic gallbladder ultrasonography with the introduction of an irritant and data of multi-moment 6-phase DS in accordance with Roman criteria III (Lacy, 2017).

Statistical analysis of the obtained results was carried out using the method of variation statistics with the determination of the average value (M), the average error $(\mathrm{m})$, followed by an assessment of the reliability of the differences using the Student's criterion. Correlation analysis was performed by determining the linear parametric Pearson correlation coefficient and the nonparametric Spearman rank correlation coefficient.

\section{Results of the Investigation}

The results indicate an intensification of FRLO processes in all the groups under study. Significant growth was observed in IDBs in all the groups surveyed (Table 1) of the primary products of FRLO. Thus, in groups 1, 2, and 3, the content of IDB was higher in comparison with PHP by 1.4 times, 1.7 times, and 1.6 times, respectively $(\mathrm{p}<0.001)$. In addition, there was a significant difference between the indicators in patients of groups 2 and 1 , which was $20.9 \%$ ( $\mathrm{p}<0.001)$, indicating the role of CNCC in the comorbidity of BA and CNCC.

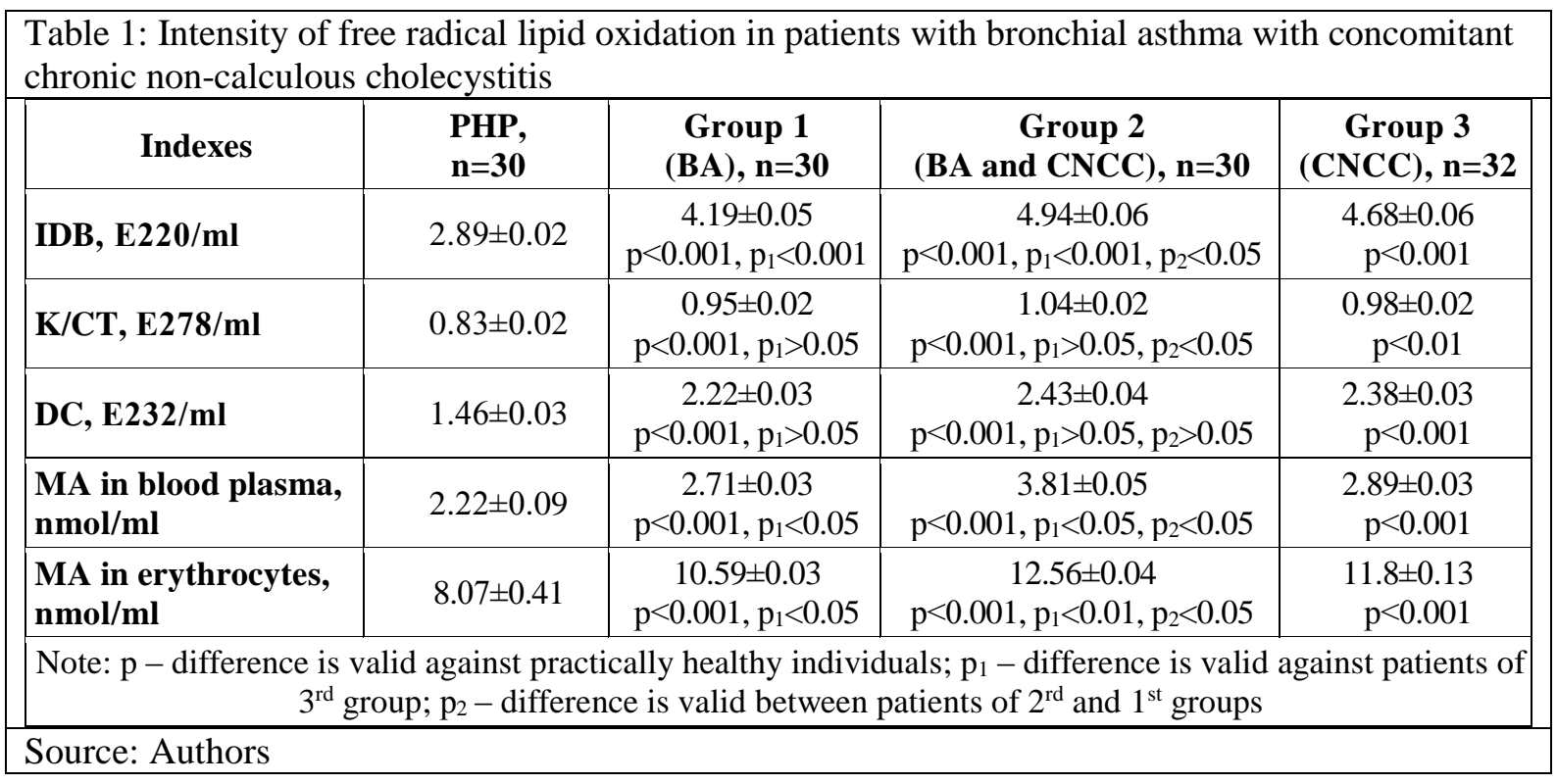


$\mathrm{K} / \mathrm{CT}$ and DC indicated a slight increase. In group 1, plasma K/CT was $12.0 \%$ higher, and DC was 1.5 times higher $(\mathrm{p}<0.05)$ compared to the PHP group. In group 2, DC and K/CT were higher by 1.7 times and by $21.7 \%$ ( $\mathrm{p}<0.05)$, respectively, compared to the PHP, which indicated the highest activation of FRLO in this group. In group 3, K/CT was higher by $16.9 \%(\mathrm{p}<0.01)$, and DC - by 1.6 times $(\mathrm{p}<0.05)$ compared to normal values.

Significant growth was observed in the final products of FRLO, especially in red blood cell MA in all groups examined (Table 1). Thus, in the patients of group 1, plasma MA and red blood cell MA were higher by $18.0 \%$ and $29.8 \%$, respectively $(\mathrm{p}<0.001)$. The highest content of plasma MA and red blood cell MA in group 2 of patients was $69.8 \%$ and $54.3 \%$, respectively $(\mathrm{p}<0.01)$. In group 3, plasma MA was $34.7 \%$ higher, and red blood cell MA was $44.4 \%$ higher $(\mathrm{p}<0.01)$ compared to normal values (Figure 1). It should be noted that there is a difference between the indicators of red blood cell MA in the examined group 2 compared to group 1 by $24.5 \%$ ( $p<0.01$ ), and plasma MA by $51.8 \%$ ( $<<0.01$ ), and a significantly smaller difference is observed between these indicators in groups 2 and 3 ( $<<0.01$ ), indicating the role of the inflammatory process in the gallbladder of patients with comorbidity course of CNCC and BA. These changes indicate a significant intensification of the FRLO processes. The increase in the level of primary and secondary products of FRLO in patients with BA and CNCC is a criterion for determining the intensity of tissue damage by active forms of oxygen and significant activation of oxidative stress.

Figure 1: Content of malonic aldehyde in blood plasma in patients with bronchial asthma and chronic non-calculous cholecystitis

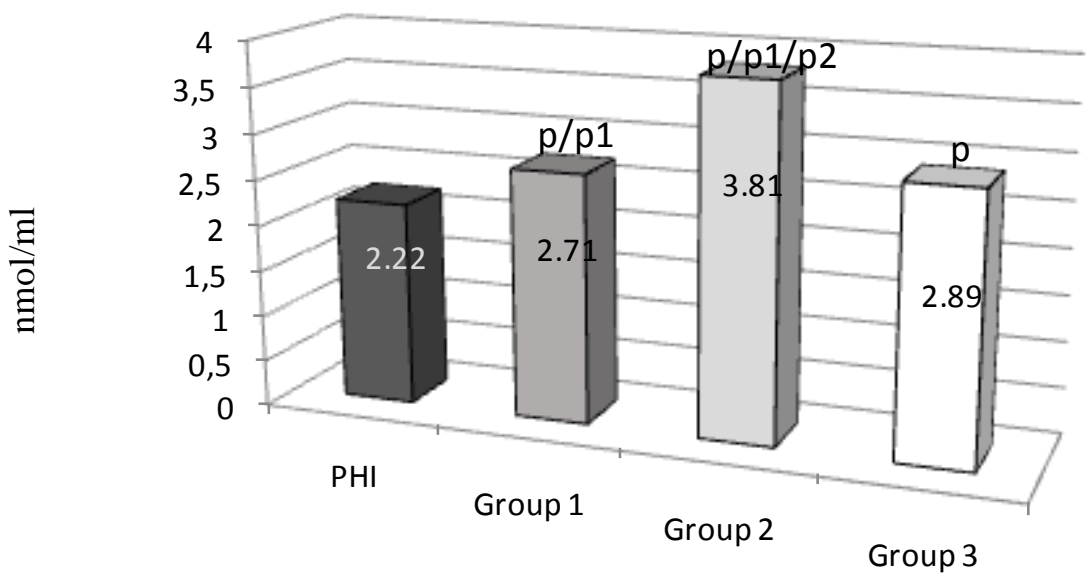

Note: $p$ - difference is valid against practically healthy individuals; $p 1$ - difference is valid against patients of 3rd group; $p 2$ - difference is valid between patients of $2 \mathrm{rd}$ and 1 st groups Source: Authors

As per the results in Table 2, indicators of primary and final products of FRLO,speed indicators of pulmonary function test, indicators of the morphological and functional condition of the gall bladder and bile homeostasis correlate with each other by varying strength.

Table 2: Correlation indexes in patients with bronchial asthma with concomitant chronic noncalculous cholecystitis

\begin{tabular}{|c|c|c|}
\hline Indexes & Correlation index & P value \\
\hline FEV1 - IDB & -0.571 & $<0.01$ \\
\hline FEV1 - DC & -0.534 & $<0.01$ \\
\hline FEV1 - MA in blood plasma & -0.502 & $<0.01$ \\
\hline FEV1 - MA in erythrocytes & -0.421 & $<0.01$ \\
\hline The thickness of the gallbladder wall - MA in blood plasma & 0.631 & $<0.01$ \\
\hline AST - MA in blood plasma & 0.570 & $<0.01$ \\
\hline Globulins - IDB & 0.695 & $<0.01$ \\
\hline Bile acids - DC & 0.542 & $<0.01$ \\
\hline Bile acids - MA in blood plasma & 0.663 & $<0.01$ \\
\hline
\end{tabular}

Source: Authors 
Table 2, reports the highest strength of correlation relationships between the parameters of homeostasis of bile and inflammation and blood levels of FRLO intermediate and final products, indicating substantial interdependence of inflammation in the gallbladder with the intensification of oxidative stress. The presence of the correlation between the intensity of LPO and FEV1 of somewhat lower strength indicates a lower proportion of BA in comorbidity and the secondary formation of broncho-obstructive syndrome against the background of CNCC.

\section{Conclusions}

The results of this study indicate the increased intensity of FRLO processes under the conditions of comorbidity of $\mathrm{BA}$ and $\mathrm{CNCC}$, primarily due to the inflammatory process in the gallbladder (the difference between the red blood cell MA and plasma MA), as well as the presence of hypoxia due to broncho-obstructive syndrome (decrease of FEV1). The increase in the level of primary (isolated double bonds, diene conjugates, ketodienes and conjugated trienes) and secondary (malonic aldehyde in erythrocytes and blood plasma) products of FRLO in patients with BA and CNCC is a criterion for determining the intensity of tissue damage by active forms of oxygen and significant activation of oxidative stress.

\section{References}

Cho Y.S., Moon H.B. (2010). The role of oxidative stress in the pathogenesis of asthma. Allergy Asthma Immunology Research 2(3), 183-187. https://doi.org/10.4168/aair.2010.2.3.183

Conte D., Fraquelli M., Giunta M., Conti C.B. (2011). Gallstones and liver disease: an overview. Journal of Gastrointestin and Liver Diseases, 20(1), 9-11. https://www.ncbi.nlm.nih.gov/pubmed/21451791

Dozor A.J. (2010). The role of oxidative stress in the pathogenesis and treatment of asthma. Annals of the New York Academy of Sciences, 1203(1), 133-137. https://doi.org/10.1111/j.1749-6632.2010.05562.x

Fabian, E., Pölöskey, P., Kósa, L., Elmadfa, I., Réthy, L. A. (2011). Activities of antioxidant enzymes in relation to oxidative and nitrosative challenges in childhood asthma. Journal of Asthma, 48(4), 351-357. https://doi.org/10.3109/02770903.2011.560319

Galimova E.S., Nurtdinova G.M., Kucher O.I. (2010). Digestive diseases in patients with bronchial asthma. Fundamental'nye issledovaniya [Fundamental Research]. 1. 36-40. (In Russian). http://www.fundamental-research.ru/ru/article/view?id=1605

International Classification of Diseases, Tenth Revision, Clinical Modification (ICD-10-CM) https://www.cdc.gov/nchs/icd/icd10cm.htm

Order of the Ministry of Health of Ukraine, about approval of Protocols for providing assistance to patients in pulmonary medicine https://zakononline.com.ua/documents/show/12588__540743

Gorbunov A.YU. (2011). Cholelithiasis: the role of motor and tonic disturbances and gallbladder inflammation in lithogenesis. Prakticheskaya medicina [Practical Medicine]. 1: 50-53. (In Russian).

Order of the Ministry of Health of Ukraine (June 13, 2005, № 271) «On Approval of Protocols on Provision of Medical Care in «Gastroenterology» Speciality» https://zakononline.com.ua/documents/show/72209_535629

Goriachkina N.M., Zhou S.D., Li C. (2010). Significance of oxidative stress parameters in bronchial asthma in patients with cold airway hyperresponsiveness. Byulleten' fiziologii i patologii dyhaniya [Bulletin Physiology and Pathology of Respiration]. 38. 12-15. (In Russian).

Lacy B.E., Patel N.K. (2017) Rome Criteria and a Diagnostic Approach to Irritable Bowel Syndrome. Journal of Clinical Medicine 6(11), 99. doi: 10.3390/jcm6110099

Iljukhina L.N., Krasavina N.P., Bashkatov V.A. (2010). Clinical and endoscopic features of lesion of gastrodyodenal zone in patients with bronchial asthma. Sibirskiy meditsinskiy zhurnal [Siberian Medical Journal]. 8. 72-74. (In Russian). 